Postprint version. Original publication in:

Journal of Insect Behavior (2007) 20:247-266

doi: http://dx.doi.org/10.1007/s10905-007-9078-z

\title{
Olfactory versus contact cues in host plant recognition of a monophagous Chrysomelid beetle
}

\author{
Annette Heisswolf ${ }^{1}$, Dirk Gabler $^{1,2}$, Elisabeth Obermaier $^{1}$, Caroline Müller $^{2}$ \\ ${ }^{1}$ Field Station Fabrikschleichach, University of Würzburg, Glashüttenstrasse 5, D-96181 Rauhenebrach \\ ${ }^{2}$ University of Würzburg, Julius-von-Sachs-Institute for Biosciences, Julius-von-Sachs Platz 3, \\ D-97082, Würzburg, Germany
}

\begin{abstract}
The importance of olfactory versus contact cues for host plant recognition was investigated in the tortoise beetle Cassida canaliculata Laich. (Coleoptera: Chrysomelidae), which is strictly monophagous on meadow sage. The reaction of adult beetles to olfactory and contact host cues was tested using three bioassays (locomotion compensator, six-chamber-olfactometer, 'stem arena') to account for different behavioral contexts. Bioassay-guided fractionation of plant extracts was elaborated to characterize the nature of contact stimuli. The beetles were only slightly attracted to odors from small amounts of leaf material. However, when contact cues were provided additionally, the beetles showed strong preferences for samples of their host plant over controls. Bioassayguided fractionation led to isolation of at least two non-polar contact stimuli acting in concert that are sufficient for host plant identification in C. canaliculata.
\end{abstract}

Keywords. Locomotion compensator, olfactometer, bioassay-guided fractionation, stem arena, host recognition.

\section{INTRODUCTION}

For herbivorous insects, a natural habitat represents a highly diverse mosaic of plants in which they must recognize cues that are emitted by their potential hosts. To find and identify their host plants, insects could use various sensory systems. A combination of visual (Bullas-Appleton et al., 2004; Fischer et al., 2004; Hausmann et al., 2004; Mäntylä et al., 2004), olfactory (Müller \& Hilker, 2000; Kalberer et al., 2001; Zhang \& Schlyter, 2004; Kalberer et al., 2005), and contact or gustatory cues (Jermy et al., 1988; Chapman \& Sword, 1993; Mitchell, 1994; Schoonhoven et al., 1998) can finally lead the insect to its food source. However, all these cues vary in both their cost of assessment and accuracy, and some cues can be more reliable than others (Fawcett \& Johnstone, 2003). For example, vision plays a role in host plant location of some herbivorous beetles (Tanton, 1977; Hausmann et al., 2004), but visual cues may be 
less accurate in complex vegetation than in open stands (Rausher, 1981; Endler, 1993; Campbell \& Borden, 2006).

Olfactory cues are likely to be signals that are more reliable. They may allow for host plant location even in a complex environment, if the insect central nervous system receives the volatile information at a fine-scale spatio-temporal resolution (Held et al., 2003; Bruce et al., 2005). Nevertheless, certain semiochemicals can also be unreliable when they are emitted by both a host and a non-host (Eisner \& Grant, 1981). Host odor specificity might be achieved through qualitative (Feeny et al., 1970; Blight et al., 1995; Bartlet et al., 1997) or quantitative (Visser \& Avé, 1978; Barata et al., 2000; van Tol \& Visser, 2002) blends of host volatiles, and/or through the relative variability of compounds among hosts and non-hosts (Wright \& Smith, 2004). Strictly monophagous herbivores may develop a great sensitivity to one or a few host-specific chemicals (Ferguson et al., 1983; Pereyra \& Bowers, 1988; Bernays, 2001).

The most accurate and reliable information about host suitability is gained via contact chemoreception. Typical behaviors before acceptance or rejection of a host are antennating, palpating, test biting, and test feeding (Harrison, 1987). On the plant surface, plant cuticular waxes can already give important information for host plant acceptance (Eigenbrode \& Espelie, 1995; Müller \& Riederer, 2005). After test-biting individual host-specific compounds can be sufficient to stimulate feeding in several specialist herbivores. The monophagous beetle Ceutorhynchus inaffectatus Gyllenhal (Coleoptera: Curculionidae) is stimulated by allyl-glucosinolate of its host plant, a Brassicaceae (Larsen et al., 1992), whereas cucurbitacin can be sufficient to stimulate feeding of some specialists on Cucurbitaceae (Metcalf et al., 1980; Tallamy \& Krischik, 1989). However, in other species feeding is stimulated only by a mixture of several compounds (Müller \& Renwick, 2001; van Loon et al., 2002), which may be inactive when offered individually, but show synergistic effects when offered together (Endo et al., 2004; Tamura et al., 2004).

The highly specialized tortoise beetle Cassida canaliculata Laich. (Coleoptera: Chrysomelidae) is strictly monophagous on meadow sage (Salvia pratensis L., Lamiales: Lamiaceae) (Wencker \& Silbermann, 1866; Bourgeois \& Scherdlin, 1899; Reitter, 1912; Graser, 1984; Trautner et al., 1989; A. Heisswolf and D. Gabler, unpublished data). Within Germany, C. canaliculata is endangered, in Bavaria it is even threatened by extinction (Kippenberg, 2003); however, on warm slopes in the nature reserve 'Hohe Wann' in Northern Bavaria, Germany ( $\left.50^{\circ} 03^{\prime} \mathrm{N}, 10^{\circ} 35^{\prime} \mathrm{E}\right)$, it is locally abundant (A. Heisswolf and E. Obermaier, personal observations). Only few details are published on the ecology of C. canaliculata (Steinhausen, 1949; Trautner et al., 1989; Heisswolf et al., 2005, 2006, 2007), and little is known about the host recognition pro- 
cess in this species. However, as monophagous herbivores the beetles should be very specifically able to recognize their host plant species $S$. pratensis.

Because $C$. canaliculata moves through its very complex habitat mainly by walking, visual cues, which may under these circumstances be of little accuracy (Endler, 1993), were neglected in the first instance. Consequently, this study focused on the attraction behavior of $C$. canaliculata to olfactory and contact cues of its host plant $S$. pratensis. Olfactory cues were analyzed in three different laboratory bioassays: (1) a locomotion compensator, (2) a six-chamber-olfactometer, and (3) a 'stem arena' (after Müller \& Hilker, 2000). These three types of assays were chosen as they present olfactory cues in different distances and modalities, and allow analyzing for different behavioral contexts (cf. Material and Methods). The beetles' reaction to contact cues was investigated only within the stem arena, as beetles were observed to preferably climb objects. Bioassay-guided fractionation of plant extracts was elaborated to characterize the nature of contact stimuli.

\section{METHODS}

\section{Insects}

Adults of C. canaliculata were collected in the 'Hohe Wann' nature reserve in Northern Bavaria, Germany (50 $\left.03^{\prime} \mathrm{N}, 10^{\circ} 35^{\prime} \mathrm{E}\right)$, between May and July 2005 . They were kept in boxes $(200 \times 200 \times 90 \mathrm{~mm})$ with a gauze lid $(500 \mu \mathrm{m}$ mesh $)$ in a climatic chamber at $20^{\circ} \mathrm{C}, 70 \%$ relative humidity, and $16 \mathrm{~L}: 8 \mathrm{D}$. The bottom of each box was covered with filter paper and the beetles were fed on leaves of $S$. pratensis.

\section{Extracts of Salvia pratensis}

Leaf material of $S$. pratensis was harvested from pre-flowering plants growing in the botanical garden of University of Würzburg, frozen, and lyophilized for $17 \mathrm{hrs}$. Dried leaves were crushed in a mortar with addition of sea sand (Merck) and extracted in $150 \mathrm{ml}$ of either $n$-hexane, dichloromethane, or methanol (Carl Roth GmbH, Karlsruhe, Germany). The three resulting extracts of different polarity were filtered and concentrated in a rotary evaporator.

As the qualitative composition of stems and leaves of $S$. pratensis has been shown to be similar (Veličković et al., 2002), both intact plant stems as well as stem dummies treated with leaf extracts were offered in the behavioral contact assays (see below for a detailed description). The volume of the extracts used in these assays corresponded to the average weight of a plant stem of $15 \mathrm{~mm}$ length and $5 \mathrm{~mm}$ diameter (like the stems used in the contact bioassays), which was $0.15 \mathrm{~g}$. The corresponding volumes for the three extracts were $8 \mu 1$ ( $n$-hexane), $5 \mu 1$ (dichloromethane), and $14 \mu 1$ (methanol). 
The $n$-hexane extract was further fractionated: $1 \mathrm{ml}$ of the extract was evaporated to dryness and the residue dissolved in $200 \mu 1$ of dichloromethane. This solution was loaded onto a column (Isolate SPE Columns $100 \mathrm{mg} \mathrm{Si}$ ) washed with dichloromethane. Elution was carried out sequentially with the following five solvents: (1) $100 \% n$-hexane, (2) $90 \% n$-hexane $+10 \%$ dichloromethane, (3) $50 \% n$-hexane + 50\% dichloromethane, (4) $90 \%$ dichloromethane $+10 \%$ methanol, and (5) $100 \%$ methanol. For each elution step, $1 \mathrm{ml}$ of the respective solvent was used and the resulting fractions were collected separately.

\section{Olfactory Bioassays: Locomotion Compensator}

The reactions of beetles to olfactory plant cues were tested in three set-ups to take different behavioral response patterns of beetles into account. First, the behavioral response of walking beetles to volatiles from different sources borne in an air stream was tested on a locomotion compensator. In this assay, an individual beetle is maintained at the top of a servosphere (300 mm Ø; Tracksphere LC 300, Syntech, Hilversum, The Netherlands) to which the air stream is directed. Two motors compensate displacements of the moving animal and pulse generators monitor the resulting movement of the sphere (Kramer, 1976), which allows the reconstruction of the tracks described by the beetle. The following four track parameters were used to quantify the beetle's behavior: (1) walking speed (mm/s); (2) straightness of walking, i.e. the quotient of vector length and total track length (ranging from 0 to 1); (3) upwind length (mm), i.e. the net distance from the origin towards the odor source along a straight line; and (4) upwind fixation, the quotient of upwind length and total track length (ranging from -1 to +1$)$.

The beetles were starved three to four hours prior to testing. Per treatment, each beetle was allowed to acclimatize on the sphere for one minute, and then one of five different odor sources was applied for four minutes. Tested odor sources were (1) five leaves (5-6 g) of S. pratensis, (2) potted, one-year-old pre-flowering S. pratensis plants withn 8-10 leaves, (3) a pot containing only soil, (4) a pure air stream, and (5) no air stream at all. The latter three treatments served as controls to test for the beetle's general walking behavior. All experiments were conducted in a dark room with a dimmed central light source above the sphere. The odor sources were presented as follows: compressed air was passed through a charcoal filter and a flask filled with distilled water to obtain a moisturized clean airflow. The airflow was passed through a flow meter, which adjusted the flow to $1200 \mathrm{ml} / \mathrm{min}$. Then the flow was passed through another flask, which contained either the materials described above or nothing for the pure air stream. The volume of the flask was 0.51 (glass flask) for the empty control and the test with leaf material and 1.01 (polyethylene flask) for the potted plant as 
well as for the pot containing only soil. Finally, the airflow ended up in the delivery tube (inner diameter: $15 \mathrm{~mm}$ ), positioned with its mid-axis the same height as, but approximately $40 \mathrm{~mm}$ away from the top of the sphere.

\section{Olfactory Bioassays: Six-Chamber-Olfactometer}

In a second assay, a static six-chamber olfactometer corresponding to the four-chamber olfactometer described by Steidle \& Schöller (1997) was used. The olfactometer was made of acrylic glass, consisting of a cylinder ( $40 \mathrm{~mm}$ high, diameter: $170 \mathrm{~mm}$ ) divided by vertical plates into six equal chambers. On top of the cylinder, a removable walking arena (diameter: $160 \mathrm{~mm})$ was placed, consisting of plastic gauze $(210 \mu \mathrm{m}$ mesh) with a rim of acrylic glass (15 $\mathrm{mm}$ high). The whole olfactometer was covered with a glass plate, and no airflow was generated.

Fresh leaf material (whole leaves) was placed in one of the chambers in either of two quantities: (1) one leaf (0.2-0.3 g; low quantity) and (2) six leaves (2.5-3.4 g, high quantity). The other five chambers remained empty and served as a control. To avoid biased results due to possible side preferences of the beetles, the position of the samples and the controls was rotated clockwise after every trial. After four trials, the leaf material was replaced. The experiments were performed in a dark room and a central light source above the olfactometer was used for illumination. Contamination of the walking arena with sample odors or possible pheromones of the beetles was avoided by cleaning the walking arenas and glass plates with ethanol and demineralized water between trials. As in nature the beetles usually walk on the lower side of plant leaves, an inverted setup was additionally tested in which the olfactometer was turned upside down and the movement of the beetles was followed by using a mirror. In this setup, three leaves (0.8-1.8 g, medium quantity) were offered.

In all settings, the beetles were starved at least two hours prior to testing. Then, each individually tested beetle was allowed to acclimatize in the arena for five minutes before the observation started. Using the software The Observer 5.0 (Noldus Information Technology, Wageningen, The Netherlands), the location (chamber) as well as the activity status (active: walking; inactive: resting, grooming) of each beetle was recorded for five minutes. The time the beetles spent walking above the chamber containing the leaf material was compared with the walking time above empty control chambers and used to assess the attractive effect of the host material.

\section{Olfactory Bioassays: Stem Arena Without Contact}

In a third assay for testing the reaction of $C$. canaliculata to olfactory cues, a 'stem arena' (according to Müller \& Hilker, 2000; Figure 1) was used, as beetles were observed to preferably climb objects. Stems of the host plant (height: $15 \mathrm{~mm}$, diameter: 5 


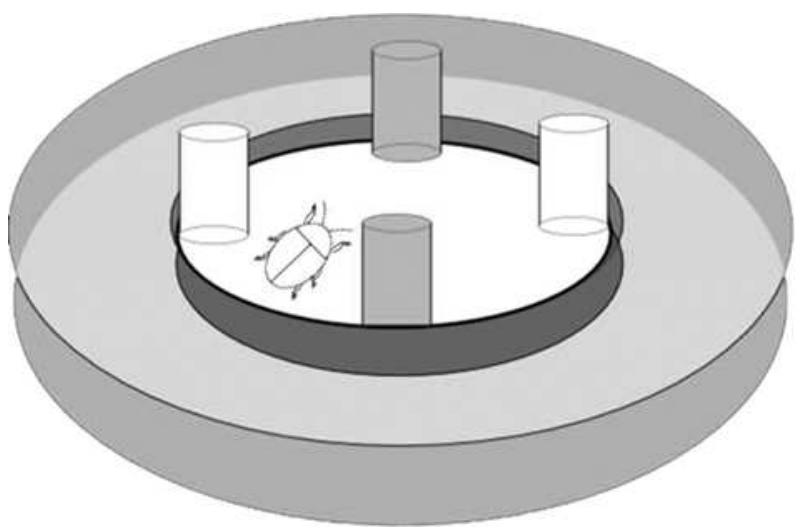

Figure 1: Stem arena used for bioassays with adults of Cassida canaliculata. Gray test stems; white control stems (each $15 \mathrm{~mm}$ high); a petri dish (diameter: $55 \mathrm{~mm}$, height: $10 \mathrm{~mm}$ ) was used as arena. Test and control stems were placed at the edge of the dish in an alternating pattern. The bottom of the arena was filled with soil and covered by a filter paper. The stem arena was placed in the bottom of a larger petri dish (diameter: $90 \mathrm{~mm}$ ) filled with water to prevent beetles from escaping. Drawing by D. Gabler and C. Müller.

$\mathrm{mm}$ ) as well as stem dummies (toothpicks) were enclosed in fine wire mesh cylinders (height: $20 \mathrm{~mm}$, diameter: $15 \mathrm{~mm}, 1 \mathrm{~mm}$ mesh) to prevent contact. In the bottom of a petri dish (diameter: $55 \mathrm{~mm}$ ), two enclosed stems and two enclosed dummies were offered to adult beetles in an alternating pattern. The bottom of the petri dish was filled with soil covered by filter paper to fix the stems and dummies. The stem arena was placed in the bottom of a larger petri dish (diameter: $90 \mathrm{~mm}$ ) filled with water to prevent beetles from escaping. The arena was surrounded with white cardboard and a central light source above the olfactometer was used for illumination.

In this arena without contact as well as in all other stem arena assays described below, the beetles were starved at least two hours prior to testing. Then, one adult beetle was placed in the center of the arena in a supine position. The time the beetles spent on test or control stems was recorded continuously for 8 minutes using the software The Observer 5.0.

\section{Olfactory Bioassays: Stem Arena With Contact}

The stem arena (Figure 1) was also used to test the role of contact cues in host recognition of $C$. canaliculata. In this assay, stems of the host S. pratensis, the non-host yarrow, Achillea millefolium L. (Asterales: Asteraceae), or stem dummies were offered to adult beetles in an alternating pattern, however, without any cover. The time the beetles spent on test or control stems was recorded continuously for 8-10 minutes.

First, it was tested whether $C$. canaliculata is able to discriminate between stems of its host plant and stems of yarrow (Achillea millefolium), a non-host plant that is 
very common in the natural habitat of $C$. canaliculata. Second, in order to account for a possible deterring effect of the non-host plant, stems of yarrow were offered against stem dummies (toothpicks). In the third experimental series, stem dummies, i.e. cigarette filters (height: $15 \mathrm{~mm}$, diameter: $5 \mathrm{~mm}$; ZIG-ZAG Slim Filters, Manchester, UK), treated with host plant extracts of different polarity (see above) were offered against stem dummies treated with the corresponding solvent only. In the fourth experimental series, the beetles' response to the five different fractions, as well as 1:1 mixtures of specific fractions of the n-hexane extract (see above) were tested against the respective solvents.

\section{Statistics}

All parameters were tested for normal distribution using the Shapiro-Wilk test. On the locomotion compensator, the parameters 'straightness' (ranging from 0 to 1 ) and 'upwind straightness' (ranging from -1 to +1 ) were arcsine-transformed prior to analysis. Walking parameters were compared between test odors and the respective controls using the Mann-Whitney $U$-Test. Additionally, upwind length and upwind straightness were tested against zero using the Mann-Whitney $U$-Test.

Differences in walking times above the six chambers in the olfactometer bioassay were compared using the Friedman test followed by the Bonferroni corrected Wilcoxon matched-pairs test. Additionally, the test chamber (containing the leaf material) was also compared to the control chamber directly opposite to the test chamber using the Wilcoxon signed-rank test for paired samples.

In the stem arena assays, the relative difference between the times spent on the test and control stem, i.e. (time on test stem - time on control stem) / total time on both stems was calculated for each beetle. The corresponding null hypothesis is that beetles have no preference, i.e. spend as much time on test as on control stems, and consequently that the relative difference between these two times is zero. The relative differences can only range from -1 (time spent completely on the control stem) to +1 (time spent completely on the test stem) and were thus arcsine- transformed prior to further analysis. The transformed differences were tested against the null hypothesis using the Mann-Whitney $U$-Test. Beetles that were inactive for more than half of the observation time were excluded from all analyses as they were considered to be not motivated. All statistical procedures were calculated with the software package R 2.2.0 for Windows (R Development Core Team, 2005). 


\section{RESULTS}

\section{Response to Volatile Cues}

On the locomotion compensator, neither of the recorded walking parameters of the beetles (walking speed, straightness, upwind length, and upwind fixation) differed significantly between the respective test and control groups (Table 1). Only in the 'pure air stream' control, upwind length $(U=112, P=0.0214, N=16)$ and upwind fixation ( $U=107, P=0.044, N=16$ ) were significantly different from zero, i.e. the beetles showed a significantly negative anemotaxis when a pure air stream was presented. Without any air stream, the beetles showed no preference for any direction (upwind length: $U=62, P=0.782, N=16$, upwind fixation: $U=60, P=0.706, N=16$ ).

In the six-chamber-olfactometer, the adult beetles of $C$. canaliculata showed no clear preference for host plant odor. When the walking times above all six chambers were compared by the Friedman test, there were no significant differences (Figure 2). However, in the 'low quantity' setting, the beetles spent significantly more time above the chamber containing leaf material of their host $S$. pratensis than above the opposite control chamber ( $W=52, P=0.010, N=10$, Fig. $2 \mathrm{~A}$ ). Both, when a 'high quantity' of leaf material was offered (Fig. 2B) and in the 'upside-down' oriented six-chamberolfactometer, where a medium leaf quantity was offered in the test chamber, the beetles were not attracted to the host plant odours (Fig. 2C). In addition, the supposedly more natural 'upside-down' setting did not result in a discernible difference in beetle behavior.

In the stem arena without contact, beetles spent similar amounts of time on covered host plant stems [median (lower and upper quartile): 88.97 (55.19-184.4) s] and corresponding empty controls [94.27 (32.48-150.1) s] $(U=99.5, P=0.556, N=18)$.

\section{Response to Contact Cues}

When beetles could choose between stems of the host meadow sage (S. pratensis) and of the non-host yarrow (A. millefolium), adults of $C$. canaliculata spent significantly more time on the stems of their host plant (Fig. 3A). However, the beetles did not discriminate between yarrow stems and dummies (toothpicks; Fig. 3B).

When the beetles could choose between dummies (cigarette filters) treated with one of the three host plant extracts of different polarity and dummies with the respective solvent alone, the beetles showed a significant preference for the $n$-hexane extract over controls (Fig. 4A). The beetles did not show a significant preference for the other two extracts (dichloromethane and methanol; Fig. 4B and C); however, a tendency towards a preference for the dichloromethane extract could be observed. 


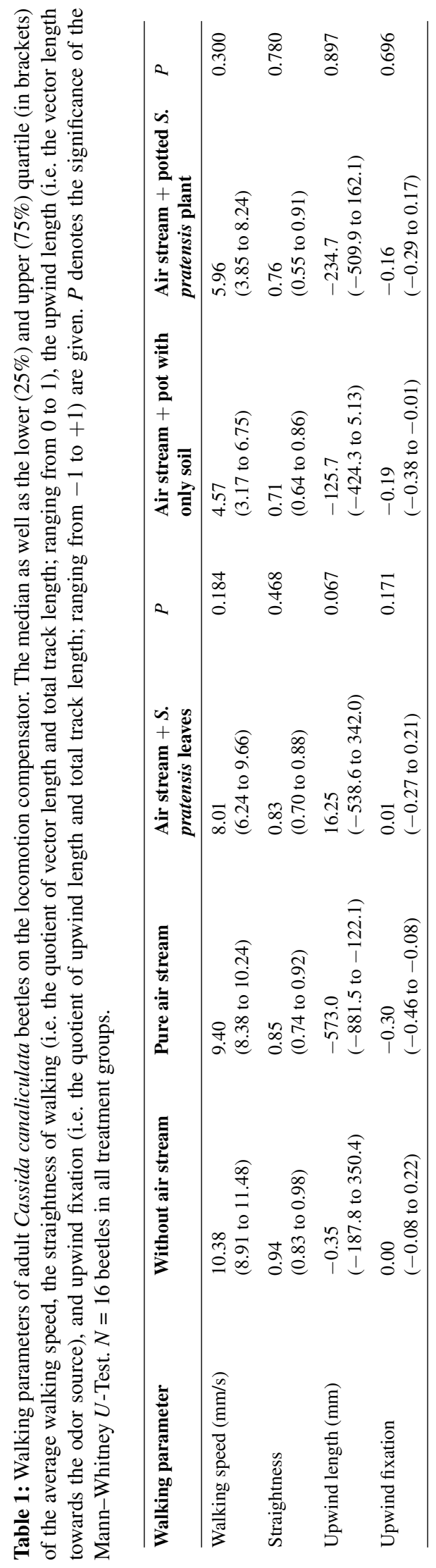




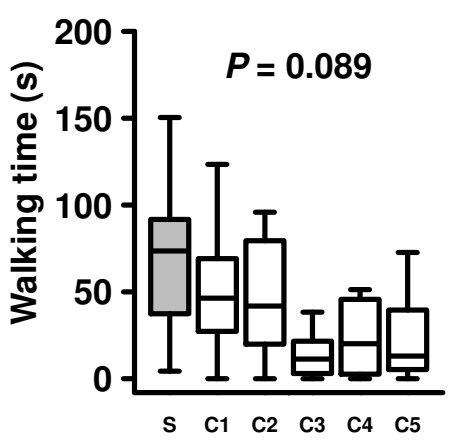

A

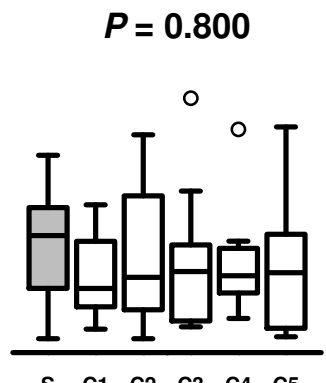

B

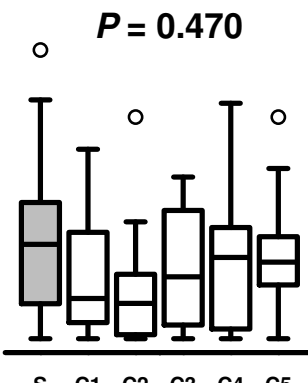

C

Figure 2: Response of adult beetles of Cassida canaliculata to volatile cues in the six-chamberolfactometer: box-and-whisker plots of the walking time (in seconds) above the chambers containing leaf material of Salvia pratensis (S, grey box) as well as above the five empty control chambers (C1-C5, white boxes). Three different amounts of leaf material were tested: (A) one leaf (0.2-0.3 g; low quantity), (B) six leaves (2.5-3.4 g; high quantity), and (C) three leaves (0.8-1.8 g; medium quantity, the latter offered in an inverted set-up of the olfactometer). The boxes represent the median, and $25 \%$ and $75 \%$ percentiles. The whiskers extend to the maximum values; the circles denote outliers. $N_{A}=10$ beetles, $N_{B}=10$ beetles, $N_{C}=15$ beetles. $P$-values of the Friedman test are given. The observation time was 5 min per beetle.

The five fractions of the $n$-hexane extract did not reveal a significant response of the beetles, however, a slight tendency of a preference for fractions 1 (100\%n-hexane) and 3 (50\% $n$-hexane, 50\% dichloromethane) could be observed (Fig. 5A-E). When the beetles were offered a 1:1 mixture of these two fractions compared with the respective mixture of solvents, the beetles significantly preferred this mixture to the control (Fig. $5 \mathrm{~F})$.

\section{Discussion}

Our results demonstrate that adults of the monophagous tortoise beetle $C$. canaliculata select their host plant chiefly by qualitative (i.e. by distinct chemical compounds) rather than quantitative (i.e. by a specific ratio of components) contact cues. The beetles showed only a very weak attraction to odors from small amounts of leaf material offered in a static six-chamber-olfactometer and were not attracted to stem odors offered upright or to leaf or whole plant odors offered in an air-stream. In contrast, when contact cues were provided additionally, the beetles strongly preferred stems of their host plant to non-hosts or controls. Bioassay-guided fractionation revealed that at least two distinct non-polar contact stimuli acting in concert are sufficient for host plant identification in C. canaliculata. 


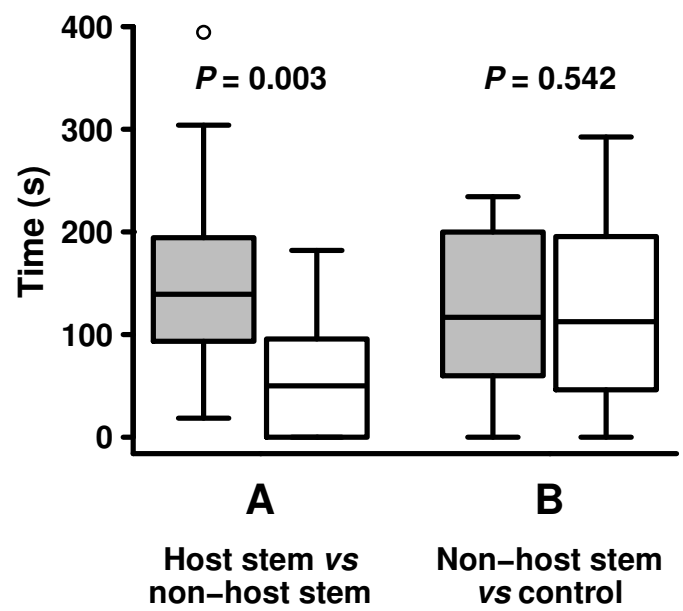

Figure 3: Response of adult beetles of Cassida canaliculata to contact cues (intact stems) in the stem arena: box-and-whisker plots of the time (in seconds) on (A) host stems (Salvia pratensis) vs. non-host stems (Achillea millefolium) and (B) non-host stems (Achillea millefolium) vs. control stems (toothpicks). The boxes represent the median, and $25 \%$ and $75 \%$ percentiles. The whiskers extend to the maximum values; the circle denotes an outlier. $N_{A}=20$ beetles, $N_{B}=18$ beetles. $P$-values of the Mann-Whitney $U$ test, comparing the mean relative difference in time spent on test and control stems to the null hypothesis of this difference being zero, are given. The observation time was 8 min per beetle.

Although several other chrysomelid species are attracted to host plant volatiles (Feeny et al., 1970; Andersen \& Metcalf, 1986; Visser, 1986; Mitchell, 1994; Müller \& Hilker, 2000, 2001; Kalberer et al., 2001, 2005), olfactory cues alone seem to be only weak stimuli in the host plant recognition process of $C$. canaliculata that mainly moves by walking rather than flying. When responses to olfactory or other cues are tested with herbivores, a negative result (i.e. no response) to odors in a bioassay could be due to different factors. The herbivores might just not respond in the tested context, the offered cues might be less or not used in their host plant searching behavior or beetles might not be motivated. Therefore, three different bioassays were employed that present odor sources in different distances, modalities, and behavioral contexts. On the locomotion compensator, where beetles could walk freely without any barrier in an air stream, they were not showing significant differences in neither of the analyzed walking parameters between the tested odor samples and the respective controls (Table 1). When only a pure air stream was offered, the beetles showed a negative anemotaxis. This behavior was also observed in several other insects (Sabelis \& Schippers, 1984; Taneja \& Guerin, 1995; van Tilborg et al., 2004) and could, for example, be a strategy to find an odor plume (Sabelis \& Schippers, 1984) or an attempt by the beetles to leave the exposed area to seek a refuge (Taneja \& Guerin, 1995). When odors of S. praten- 


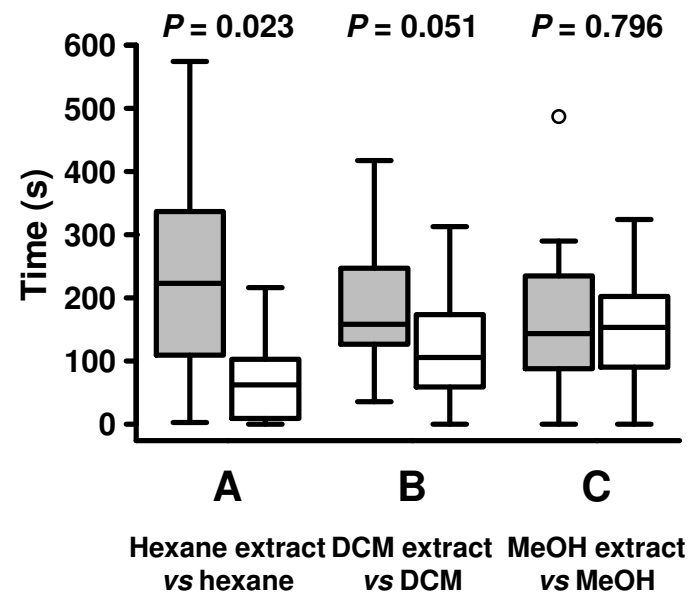

Figure 4: Response of adult beetles of Cassida canaliculata to contact cues (host plant extracts) in the stem arena: box-and-whisker plots of the time (in seconds) on test and control stem dummies (cigarette filters). (A) $n$-hexane extract vs. $n$-hexane, (B) dichloromethane (DCM) extract vs. DCM, and (C) methanol $(\mathrm{MeOH})$ extract vs. $\mathrm{MeOH}$. The boxes represent the median, and $25 \%$ and $75 \%$ percentiles. The whiskers extend to the maximum values; the circle denotes an outlier. $N_{A}=18$ beetles, $N_{B}=19$ beetles, $N_{C}=17$ beetles. $P$-values of the Mann-Whitney $U$-test, comparing the mean relative difference in time spent on test and control stems to the null hypothesis of this difference being zero, are given. The observation time was 10 min per beetle.

sis leaves or whole plants were borne in the air stream, the beetles showed neither a positive nor a negative anemotaxis, however, a tendency of a difference $(P=0.067)$ could be seen comparing upward length between the 'pure air stream' control and the odor of S. pratensis leaves (Table 1). Variation in flow-rate (1000-3000 $\mathrm{ml} / \mathrm{min}$, data not shown) did not result in a changed walking behavior. Given the observation that C. canaliculata moves through its habitat (i.e. dense and richly structured meadows) mainly by walking, the strong incentive of walking downwind (possibly searching for a refuge) may have concealed any positive reactions to host plant odor.

When plant volatiles were provided without air stream in a static six-chamber olfactometer, beetles showed a slight attraction to odors from low amounts of leaf material (Fig. 2A). Although the median walking time above (Fig. 2B) or below (Fig. 2C) the chamber with high or intermediate amounts of leaves was also higher than on controls, these differences were not significant. The walking chamber of the olfactometer might have been already satiated with odor within the five minutes testing time when offering higher quantities of plant material. Finally, in the open stem arena, the air could not satiate and beetles had very close access to plant parts, i.e. they could and readily did climb the wire mesh coverings around stems. Nevertheless, beetles showed 


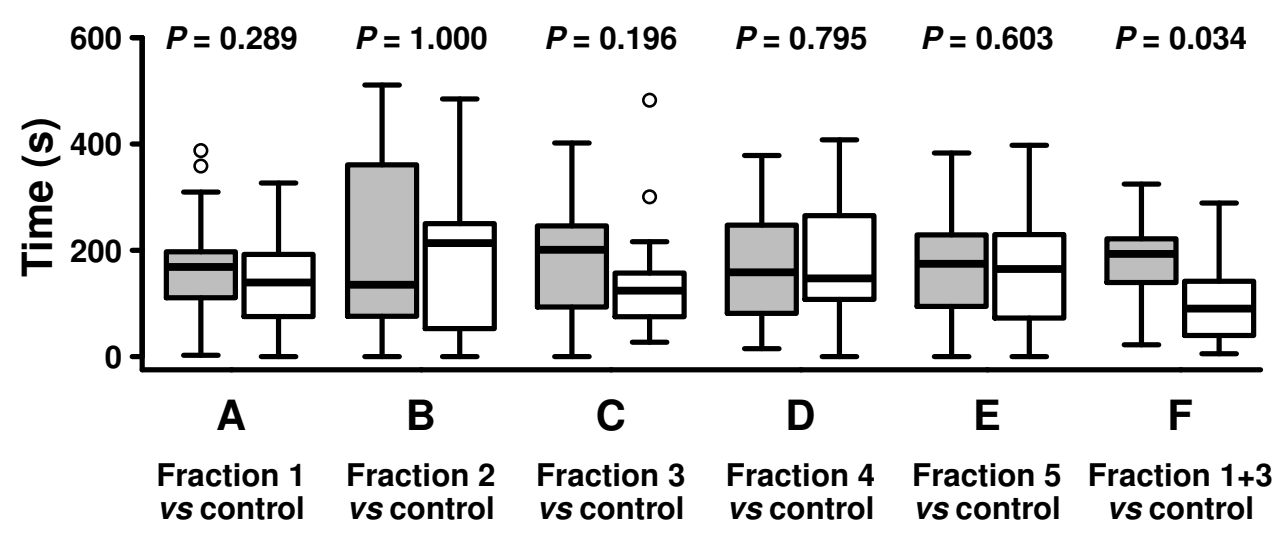

Figure 5: Response of adult beetles of Cassida canaliculata to contact cues (fractions of the n-hexane extract of Salvia pratensis leaves) in the stem arena: box-and-whisker plots of the time (in seconds) on test and control stem dummies (cigarette filters). The fractions were eluted in (1) $100 \% n$-hexane, (2) $90 \%$ $n$-hexane $+10 \%$ dichloromethane, (3) 50\% n-hexane $+50 \%$ dichloromethane, (4) $90 \%$ dichloromethane $+10 \%$ methanol, and (5) $100 \%$ methanol. The boxes represent the median, and $25 \%$ and $75 \%$ percentiles. The whiskers extend to the maximum values; the circles denote outliers. $N_{A}=16$ beetles, $N_{B}=13$ beetles, $N_{C}=18$ beetles, $N_{D}=18$ beetles, $N_{E}=17$ beetles, $N_{F}=18$ beetles. $P$-values of the Mann-Whitney $U$ test, comparing the mean relative difference in time spent on test and control stems to the null hypothesis of this difference being zero, are given. The observation time was 10 (A-E) or 8 min (F) per beetle.

no arrestment on their hosts. Thus, in total, we consider the response to volatile cues alone as rather weak.

In nature, however, beetles most probably will encounter olfactory host plant cues in combination with visual cues, which might enhance the beetles' response to host plant volatiles (Prokopy \& Owens, 1983; Blackmer \& Cañas, 2005). A recent study by Heisswolf et al. (2007) showed that $C$. canaliculata beetles could find their host plant from a distance of at maximum $50 \mathrm{~cm}$, when a plant individual was offered in a semi-natural arena. However, whether visual or olfactory cues alone or in combination attracted the beetles could not be discriminated. The practical importance of both visual and olfactory cues for host plant finding in diverse and richly structured meadows has still to be elucidated, as beetles will not encounter isolated plants (as in the arena assay) in their natural habitat.

When beetles had direct access to the host plant material in the stem arena, they were very well able to discriminate their host plant based on contact cues. They clearly preferred stems of their host S. pratensis to stems of the non-host A. millefolium (Fig. $3 \mathrm{~A})$. Moreover, the indiscriminative response to stems of A. millefolium compared to stem dummies (toothpicks; Fig. 3A) showed that the beetles were neither arrested by any (un)specific plant compounds nor deterred by this non-host plant. 
Non-polar chemical stimuli were sufficient to cause arrestment in $C$. canaliculata (Fig. 4A). Physical cues, i.e. the intact morphology of the stem or leaf surface, were not necessary for host plant recognition, since the beetles could discriminate dummies treated with host plant extract from dummies treated only with the solvent. This has been also found for another Cassida species (Müller \& Hilker, 2001) and might be a general pattern within this genus. Nevertheless, physical cues might act additively or synergistically with contact cues in host recognition (Müller \& Hilker, 2001; Müller \& Riederer, 2005).

The quantitative composition of compounds in the tested host plant extracts was certainly quite different from the ratios and amounts that the beetles would perceive from intact plants in nature. However, as the beetles were readily able to identify their host plant from extracts when direct contact was given, the presence of particular host plant compounds seem to be more important for the specialist $C$. canaliculata than a specific ratio or amount of these compounds. The use of qualitative cues such as the presence of single compounds or a mixture of specific compounds for host plant identification has also been reported from other specialized leaf beetles (Rees, 1969; Larsen et al., 1992; Müller \& Renwick, 2001). Thus, one might hypothesize, that in contact chemoreception the quantity, i.e. the relative ratio of compounds, is not as essential as in olfactory host plant identification, where the majority of herbivorous insects seem to respond only to very specific ratios of host plant volatiles (reviewed by Bruce et al., 2005).

Moreover, we also found that one contact stimulus alone is not sufficient for host recognition in C. canaliculata. Whereas individually tested fractions of the attractive $n$-hexane-extract did not reveal a significant response, a mixture of fraction $1(100 \%$ $n$-hexane) and fraction 3 (50\% $n$-hexane $+50 \%$ dichloromethane) was significantly arresting (Fig. 5F). The fact that these two synergistically active fractions of the $n$-hexane extract were separated by an unattractive fraction (fraction 2) implies that there have to be at least two or more substances involved. The observed tendency of a preference towards the dichloromethane extract further supports this hypothesis, since this extract may have contained one of the active compounds also soluble in fraction 3. Thus, we can conclude that $C$. canaliculata needs at least two contact stimuli acting in concert to identify its host plant $S$. pratensis. Use of just one compound might be misleading if it is not entirely specific for $S$. pratensis. Comparing again contact to olfaction, ours and other results indicate that in both contact (Städler \& Buser, 1984; Hopkins et al., 1997; Müller \& Renwick, 2001; van Loon et al., 2002; Endo et al., 2004; Tamura et al., 2004) and olfaction (Fraser et al., 2003; Bruce et al., 2005) a blend of compounds can be necessary for host plant identification. 
In the $n$-hexane extract, characteristic monoterpenes (e.g. $\beta$-pinene, 1,8-cineole) and sesquiterpenes (germacrene $\mathrm{D}, \beta$-caryophyllene) of $S$. pratensis (Hegnauer, 1964; Veličković et al., 2002) as well as typical components of cuticular waxes (Müller \& Riederer, 2005) could be detected (D. Gabler and C. Müller, data not shown) that could potentially act as arrestants.

In summary, the results of this study indicate the following scenario for the host recognition process of the monophagous herbivore $C$. canaliculata. The beetles move mainly by walking rather than flying through their complex natural environment. A combination of olfactory and visual cues might direct the beetles towards their host plant, however, the practical importance of these cues needs to be corroborated under natural conditions. After contact evaluation, the presence of at least two distinct compounds is giving reliable information for arrestment at that plant.

\section{ACKNOWLEDGEMENTS}

We thank Torsten Meiners and Monika Hilker for giving us the opportunity to use the servosphere at Free University, Berlin, and Oliver Mitesser and Thomas Hovestadt for statistical advice. We are grateful to Hans Joachim Poethke for valuable discussions during the development of the concept as well as to Markus Riederer for hosting the project. Furthermore, we appreciate the helpful comments of two anonymous referees. We thank the government of Lower Franconia (Bavaria, Germany) for the permission to collect beetles in the nature reserve. A. Heisswolf was financially supported through a scholarship granted by the Evangelisches Studienwerk e.V. Villigst. Financial support for the experiments was granted by the Sonderforschungsbereich SFB 554 'Mechanismen und Evolution des Arthropodenverhaltens: Gehirn - Individuum - soziale Gruppe - Superorganismus' of the Deutsche Forschungsgemeinschaft.

\section{REFERENCES}

Andersen, J. F. \& Metcalf, R. L. (1986). Identification of a volatile attractant for Diabrotica and Acalymma spp. from blossoms of Cucurbita maxima duchesne. Journal of Chemical Ecology 12: 687-699. 11

Barata, E. N., Pickett, J. A., Wadhams, L. J., Woodcock, C. M. \& Mustaparta, H. (2000). Identification of host and nonhost semiochemicals of eucalyptus woodborer Phoracantha semipunctata by gas chromatographyelectroantennography. Journal of Chemical Ecology 26: 1877-1895. 2

Bartlet, E., Blight, M. M., Lane, P. \& Williams, I. H. (1997). The responses of the cabbage seed weevil Ceutorhynchus assimilis to volatile compounds from oilseed rape in a linear track olfactometer. Entomologia Experimentalis et Applicata 85: 257-262. 2

Bernays, E. A. (2001). Neural limitations in phytophagous insects: Implications for diet breadth and evolution of host affiliation. Annual Review of Entomology 46: 703-727. 2 
Blackmer, J. L. \& Cañas, L. A. (2005). Visual cues enhance the response of Lygnus hesperus (Heteroptera: Miridae) to volatiles from host plants. Environmental Entomology 34: 1524-1533. 13

Blight, M. M., Pickett, J. A., Wadhams, L. J. \& Woodcock, C. M. (1995). Antennal perception of oilseed rape, Brassica napus (Brassicaceae), volatiles by the cabbage seed weevil Ceutorhynchus assimilis (Coleoptera, Curculionidae). Journal of Chemical Ecology 21: 1649-1664. 2

Bourgeois, J. \& Scherdlin, P. (1899). Catalogue des Coléoptères des Vosges et des regions limitrophes. Decker, Colmar. 2

Bruce, T. J. A., Wadhams, L. J. \& Woodcock, C. M. (2005). Insect host location: a volatile situation. Trends in Plant Science 10: 269-274. 2, 14

Bullas-Appleton, E. S., Otis, G., Gillard, C. \& Schaafsma, A. W. (2004). Potato leafhopper (Homoptera: Cicadellidae) varietal preferences in edible beans in relation to visual and olfactory cues. Environmental Entomology 33: 13811388. 1

Campbell, S. A. \& Borden, J. H. (2006). Integration of visual and olfactory cues of hosts and non-hosts by three bark beetles (Coleoptera: Scolytidae). Ecological Entomology 31: 437-449. 2

Chapman, R. F. \& Sword, G. (1993). The importance of palpation in food selection by a polyphagous grasshopper (Orthoptera: Acrididae). Journal of Insect Behavior 6: 79-91. 1

Eigenbrode, S. D. \& Espelie, K. E. (1995). Effects of plant epicuticular lipids on insect herbivores. Annual Review of Entomology 40: 171-194. 2

Eisner, T. \& Grant, R. P. (1981). Toxicity, odor aversion, and 'odor aposematism'. Science 213: 476. 2

Endler, J. A. (1993). The color of lights in forests and its implications. Ecological Monographs 63: 1-27. 2, 3

Endo, N., Abe, M., Sekine, T. \& Matsuda, K. (2004). Feeding stimulants of Solanaceae-feeding lady beetle, Epilachna vigintioctomaculata (Coleoptera: Coccinellidae) from potato leaves. Applied Entomology and Zoology 39: 411416. 2,14

Fawcett, T. W. \& Johnstone, R. A. (2003). Optimal assessment of multiple cues. Proceedings of the Royal Society B: Biological Sciences 270: 1637-1643. 1

Feeny, P., Paauwe, K. L. \& Demong, N. J. (1970). Flea beetles and mustard oils: Host plant specificity of Phyllotreta cruciferae and P. striolata adults (Coleoptera: Chrysomelidae). Annals of the Entomological Society of America 63: $832-841.2,11$

Ferguson, J. E., Metcalf, E. R., Metcalf, R. L. \& Rhodes, A. M. (1983). Influence of cucurbitacin content in cotyledons of Cucurbitaceae cultivars upon feeding behavior of Diabroticine beetles (Coleoptera: Chrysomelidae). Journal of Economic Entomology 76: 47-51. 2

Fischer, S., Samietz, J., Wäckers, F. L. \& Dorn, S. (2004). Perception of chromatic cues during host location by the pupal parasitoid Pimpla turionellae (L.) (Hymenoptera: Ichneumonidae). Environmental Entomology 33: 81-87. 1

Fraser, A. M., Mechaber, W. L. \& Hildebrand, J. G. (2003). Electroantennographic and behavioral responses of the sphinx moth Manduca sexta to host plant headspace volatiles. Journal of Chemical Ecology 29: 1813-1833. 14

Graser, K. (1984). Thüringer Funde von Cassida (U. G. Lordiconia RTTR) canaliculata LAICH. 1781 (Col., Chrysomelidae). Entomologische Nachrichten und Berichte 28: 86-87. 2

Harrison, G. D. (1987). Host-plant discrimination and evolution of feeding preference in the Colorado potato beetle Leptinotarsa decemlineata. Physiological Entomology 12: 407-415. 2

Hausmann, C., Samietz, J., \& Dorn, S. (2004). Visual orientation of overwintered Anthonomus pomorum (Coleoptera: Curculionidae). Environmental Entomology 33: 1410-1415. 1 
Hegnauer, R. (1964). Chemotaxonomie der Pflanzen. Birkhäuser Verlag, Basel. 15

Heisswolf, A., Obermaier, E. \& Poethke, H. J. (2005). Selection of large host plants for oviposition by a monophagous leaf beetle: nutritional quality or enemy-free space? Ecological Entomology 30: 299-306. 2

Heisswolf, A., Poethke, H. J. \& Obermaier, E. (2006). Multitrophic influences on egg distribution in a specialized leaf beetle at multiple spatial scales. Basic and Applied Ecology 7: 565-576. 2

Heisswolf, A., Ulmann, S., Obermaier, E., Mitesser, O. \& Poethke, H. J. (2007). Host plant finding in the specialised leaf beetle Cassida canaliculata - an analysis of small-scale movement behaviour. Ecological Entomology 32: 194-200. 2, 13

Held, D. W., Gonsiska, P. \& Potter, D. A. (2003). Evaluating companion planting and non-host masking odors for protecting roses from the Japanese beetle (Coleoptera: Scarabaeidae). Journal of Economic Entomology 96: 8187. 2

Hopkins, R. J., Birch, A. N. E., Griffiths, D. W., Baur, R., Städler, E. \& McKinlay, R. G. (1997). Leaf surface compounds and oviposition preference of Turnip root fly Delia floralis: the role of glucosinolate and nonglucosinolate compounds. Journal of Chemical Ecology 23: 629-643. 14

Jermy, T., Szentesi, A. \& Horváth, J. (1988). Host plant finding in phytophagous insects: the case of the Colorado potato beetle. Entomologia Experimentalis et Applicata 49: 83-98. 1

Kalberer, N. M., Turlings, T. C. J. \& Rahier, M. (2001). Attraction of a leaf beetle (Oreina cacaliae) to damaged host plants. Journal of Chemical Ecology 27: 647-661. 1, 11

Kalberer, N. M., Turlings, T. C. J. \& Rahier, M. (2005). An alternative hibernation strategy involving sunexposed "hotspots", dispersal by flight, and host plant finding by olfaction in an alpine leaf beetle. Entomologia Experimentalis et Applicata 114: 189-196. 1, 11

Kippenberg, H. (2003). Rote Liste gefährdeter Blatt- und Samenkäfer (Coleoptera: Chrysomelidae et Bruchidae) Bayerns. In: für Umweltschutz, B. L. (ed.) Rote Liste gefährdeter Tiere Bayerns, vol. 166, Schriftenreihe des LfU, pp. 154-160. 2

Kramer, E. (1976). The orientation of walking honeybees in odour fields with small concentration gradients. Physiological Entomology 1: 27-37. 4

Larsen, L. M., Nielsen, J. K. \& Sørensen, H. (1992). Host plant recognition in monophagous weevils: Specialization of Ceutorhynchus inaffectatus to glucosinolates from its host plant Hesperis matronalis. Entomologia Experimentalis et Applicata 64: 49-55. 2, 14

Mäntylä, E., Klemola, T. \& Haukioja, E. (2004). Attraction of willow warblers to sawfly-damaged mountain birches: novel function of inducible plant defences? Ecology Letters 7: 915-918. 1

Metcalf, R. L., Metcalf, R. A. \& Rhodes, A. M. (1980). Cucurbitacins as kairomones for diabroticite beetles. Proceedings of the National Academy of Sciences 77: 3769-3772. 2

Mitchell, B. K. (1994). The chemosensory basis of host-plant recognition in Chrysomelidae. In: Jolivet, P. H., Cox, M. L. \& Petitpierre, E. (eds.) Novel Aspects of the Biology of Chrysomelidae, Kluwer Academic Publishers, Dordrecht, pp. 141-151. 1, 11

Müller, C. \& Hilker, M. (2000). The effect of a green leaf volatile on host plant finding by larvae of a herbivorous insect. Naturwissenschaften 87: 216-219. 1, 3, 5, 11

Müller, C. \& Hilker, M. (2001). Host finding and oviposition behavior in a chrysomelid specialist - the importance of host plant surface waxes. Journal of Chemical Ecology 27: 985-994. 11, 14

Müller, C. \& Renwick, J. A. A. (2001). Different phagostimulants in potato foliage for Manduca sexta and Leptinotarsa decemlineata. Chemoecology 11: 37-41. 2, 14 
Müller, C. \& Riederer, M. (2005). Review: Plant surface properties in chemical ecology. Journal of Chemical Ecology 31: $2621-2651.2,14,15$

Pereyra, P. C. \& Bowers, M. D. (1988). Iridoid glycosides as oviposition stimulants for the buckeye butterfly, Junonia coenia. Journal of Chemical Ecology 14: 917-928. 2

Prokopy, R. J. \& Owens, E. D. (1983). Visual detection of plants by herbivorous insects. Annual Review of Entomology 28: $337-364.13$

R Development Core Team (2005). R: A language and environment for statistical computing. R Foundation for Statistical Computing, Vienna, Austria, URL http://www.r-project.org. 7

Rausher, M. D. (1981). The effect of native vegetation on the susceptibility of Aristolochia reticulata (Aristolochiaceae) to herbivore attack. Ecology 62: 1187-1195. 2

Rees, C. J. C. (1969). Chemoreceptor specificity associated with choice of feeding site by the beetle Chrysolina brunsvicensis on its foodplant, Hypericum hirsutum. Entomologia Experimentalis et Applicata 12: 565-583. 14

Reitter, E. (1912). Fauna Germanica, Käfer. Lutz, Stuttgart. 2

Sabelis, M. W. \& Schippers, P. (1984). Variable wind directions and anemotactic strategies of searching for an odor plume. Oecologia 63: 225-228. 11

Schoonhoven, L. M., Jermy, T. \& van Loon, J. J. A. (1998). Host-plant selection: how to find a host plant. In: Schoonhoven, L. M., Jermy, T. \& Loon van, J. J. A. (eds.) Insect-Plant Biology: From Physiology to Evolution, Chapman \& Hall, London, pp. 121-153. 1

Städler, E. \& Buser, H. R. (1984). Defense chemicals in leaf surface wax synergistically stimulate oviposition by a phytophagous insect. Experientia 40: 1157-1159. 14

Steidle, J. L. M. \& Schöller, M. (1997). Olfactory host location and learning in the granary weevil parasitoid Lariophagus distinguendus (Hymenoptera: Pteromalidae). Journal of Insect Behavior 10: 331-342. 5

Steinhausen, W. (1949). Morphologie, Biologie und Ökologie der Entwicklungsstadien der in Niedersachsen heimischen Schildkäfer (Cassidinae Chrysomelidae Coleoptera) und deren Bedeutung für die Landwirtschaft. Ph.D. thesis, Technische Hochschule Braunschweig. 2

Tallamy, D. W. \& Krischik, V. A. (1989). Variation and function of cucurbitacins in Cucurbita: an examination of current hypothesis. American Naturalist 133: 766-786. 2

Tamura, Y., Hattori, M., Konno, K., Kono, Y., Honda, H., Ono, H. \& Yoshida, M. (2004). Triterpenoid and caffeic acid derivatives in the leaves of ragweed, Ambrosia artemisiifolia L. (Asterales: Asteraceae), as feeding stimulants of Ophraella communa LeSage (Coleoptera: Chrysomelidae). Chemoecology 14: 113-118. 2, 14

Taneja, J. \& Guerin, P. M. (1995). Oriented responses of the triatomine bugs Rhodnius prolixus and Triatoma infestans to vertebrate odours on a servosphere. Journal of Comparative Physiology A 176: 455-464. 11

Tanton, M. T. (1977). Response to food plant stimuli by larvae of the mustard beetle Phaedon cochleriae. Entomologia Experimentalis et Applicata 22: 113-122. 1

Trautner, J., Geigenmüller, K. \& Bense, U. (1989). Käfer beobachten, bestimmen. Neumann-Neudamm, Melsungen. 2

van Loon, J. J. A., Wang, C. Z., Nielsen, J. K., Gols, R. \& Qui, Y. T. (2002). Flavonoids from cabbage are feeding stimulants for diamondback moth larvae additional to glucosinolates: chemoreception and behaviour. Entomologia Experimentalis et Applicata 104: 27-34. 2, 14

van Tilborg, M., Sabelis, M. W. \& Roessingh, P. (2004). State-dependent and odour-mediated anemotactic responses of the predatory mite Phytoseiulus persimilis in a wind tunnel. Experimental and Applied Acarology 32: 263-270. 11 
van Tol, R. W. H. M. \& Visser, J. H. (2002). Olfactory antennal responses of the vine weevil Otiorhynchus sulcatus to plant volatiles. Entomologia Experimentalis et Applicata 102: 49-64. 2

Veličković, D. T., Randjelović, N. V., Ristić, M. S., Šmelcerović, A. A. \& Veličković, A. S. (2002). Chemical composition and antimicrobial action of the ethanol extracts of Salvia pratensis L., Salvia glutinosa L. and Salvia aethiopis L. Journal of the Serbian Chemical Society 67: 639-646. 3, 15

Visser, J. H. (1986). Host odor perception in phytophagous insects. Annual Review of Entomology 31: 121-144. 11

Visser, J. H. \& Avé, D. A. (1978). General green leaf volatiles in the olfactory orientation of the Colorado beetle, Leptinotarsa decemlineata. Entomologia Experimentalis et Applicata 24: 738-749. 2

Wencker, J. \& Silbermann, G. (1866). Catalogue des Coléoptères de l'Alsace et des Vosgues. Silbermann, Strasbourg. 2

Wright, G. A. \& Smith, B. H. (2004). Variation in complex olfactory stimuli and its influence on odour recognition. Proceedings of the Royal Society London B 271: 147-152. 2

Zhang, Q. H. \& Schlyter, F. (2004). Olfactory recognition and behavioural avoidance of angiosperm nonhost volatiles by conifer-inhabiting bark beetles. Agricultural and Forest Entomology 6: 1-19. 1 